\title{
Algunos comentarios a las pruebas de permeabilidad tubárica
}

\author{
DR. RICARDo RUEDA G.
}

Adjunto del Depatramento de Ginecología del Hospital San José de Bogotá.

Muchos son los casos de infertilidad femenina en que se impone practicar pruebas de permeabilidad tubárica ya que cuando se sospecha el "factor trompa" como responsable del problema, éstas aclaran la dificultad satisfactoriamente.

Son de todos conocidas las pruebas que como la insuflación quimográfica y la histerosalpingografía aseguran la existencia o no de permeabilidad normal o disminuída, la longitud de la tuba y las anomalías que puedan existir, pero que no demuestran una fisiología normal o patológica como lo afirman en sus estudios Bunster, Stabile, Cónil y otros.

Ahora bien, son muchos los autores que pretenden afirmar que las oscilaciones obtenidas en las gráficas de insuflación quimográfica, o las imágenes radiológicas demuestran el estado funcional de la trompa, siendo que otros han comprobado que estos cambios no se deben a la función activa tubárica, sino simplemente a cambios de la presión intrauterina que hacen franquear el esfinter cornual.

La motilidad tubárica es suave y sostenida como lo han podido demostrar Doyle y otros mediante la culdoscopia, pero esta motilidad no parece ser el único factor junto con la permeabilidad indispensables para la progresión del huevo. Los cilios vibrátiles y la denominada "corriente serosa" deben jugar indudablemente un papel de importancia desde el momento en que sufren rambios definidos y comprobados durante el ciclo menstrual.

De estas funciones al fin y al cabo las que pueden ser estudiadas con la insuflación o el salpingograma, son las pasivas o de permeabilidad. 
Además de las funciones anotadas, tiene la trompa dos más, no menos importantes como son las de captación y nutrición, que se conservan aún en trompas que han sido sometidas a procedimientos quirúrgicos conservadores, pero que se alteran considerablemente en muchos procesos infecciosos, adquiriendo la trompa un estado de rigidez más o menos pronunciado que todos hemos tenido oportunidad de observar.

Finalmente, para terminar estas breves consideraciones de orden fisiológico, vale la pena anotar que los autores de la escuela española, entre los que se destaca especialmente Conil Serra, han demostrado claramente la dirección descendente de la corriente tubárica.

¿Y cómo establecer entonces si las funciones de captación, transporte y nutrición de la trompa se encuentran indemnes, o si por el contrario están alteradas dificultando o impiaiendo el transporte del óvulo?

Se han ideado ya desde hace algunos años las denominadas "pruebas descendentes" de la permeabilidad tubárica, que al parecer se ajustan más a los postulados de la fisiología de la trompa de' Falopio.

En 1949 la escuela española practicaba inyecciones de aceite neutro de oliva dentro de la cavidad abdominal, reconociendo su presencia a las 24 horas en el tapón mucoso cervical; es la prueba denominada Oleotransporte.

Con la misma finalidad practicaron inyecciones intra-abdominales de prontosíl rubrum, para reconocer a los pocos minutos su presencia en el canal cervical.

En los Estados Unidos de Norteamérica Deker introdujo granos de almidón en el fondo de saco de Douglas. Pendelton y Tompkins proponen la inyección intraperitoneal de una pequeña cantidad de tinta china, colocando a continuación un tapón de algodón sobre el cuello para reconocer las sustancias mencionadas.

Además de los elementos anotados, se han ensayado con el mismo fin la introducción de pequeñísimas esferas de polimetracrilato de metilo, huevos de áscaris, colorantes varios y carbón y los resultados difieren en ocasiones de los obtenidos con las pruebas ascendentes. 
Es pues, interesante tener en cuenta estas pruebas que aunque se encuentran todavía en estudio experimental pueden aclarar muchos problemas del factor tubárico en la esterilidad femesina, especialmente si persiste la infertilidad en un determinado caso a pesar de la negatividad de todos los factores y en presencia de pruebas ascendentes satisfactorias.

Estas observaciones merecen meditación y estudio, y es posible que lleguen algún día a poner en claro y a resolver situaciones difíciles de la esterilidad femenina.

\section{BIBLIOGRAFIA}

1. ENGLE, EARL T.-"Diagnóstico y tratamiento de la esterilidad humana”. I. Ed. "Beta”. Buenos Aires. 1948.

2. DECKER ALBERT.-“Culdoscopy”. I. Ed. Saunders Company. London. 1952.

3. CONILL SERRA V.- "Lecciones sobre exploración Ginecológica". I. Ed. Editorial Labor, S. A. Barcelona. 1955.

4. RUEDA G. RICARDO.--"Contribución al estudio radiológico de las trompas de Falopio. "Rev. Col. de Obst. y Gin." V. N. 1955. 